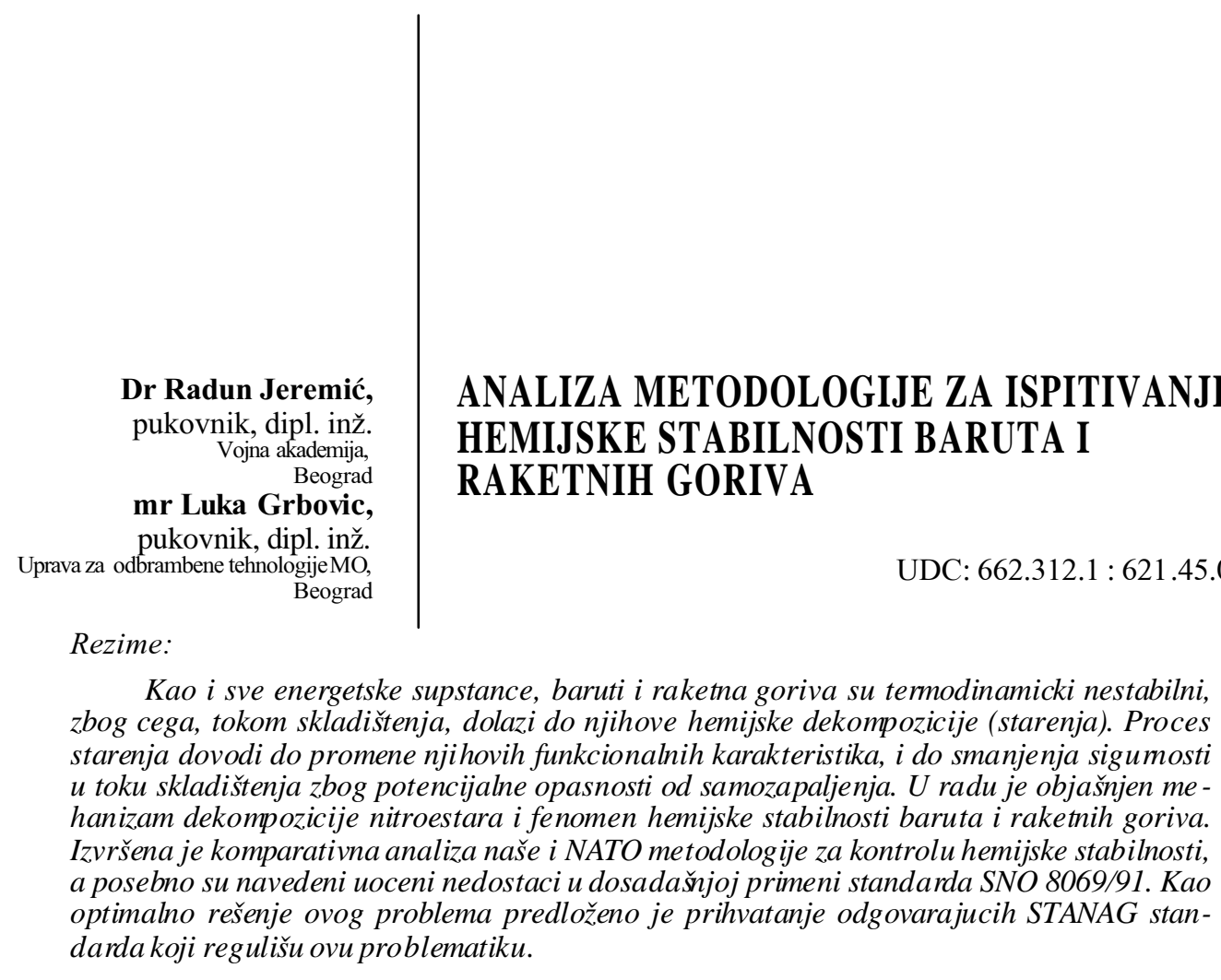

Ključne reči: baruti, raketna goriva, hemijska stabilnost, standard.

\title{
THE ANALISYS OF METHODOLOGY FOR INVESTIGATION OF CHEMICAL STABILITY OF PROPELLANTS
}

Summary:

As the other energetic substances, propellants are thermodynamically unstable. Thereby, during storing, they undergo chemical decomposition process (aging). Aging process are cause changing their functional properties and decreasing safe during storage because of potential hazard from self ignition. The decomposition mechanism of nitro esters and chemical stability fenomen of propellants are shortly discussed in these papers. The compared analisys of domestic and NATO methodology for investigation of chemical stability is realized. The observed deficiencies in up to now application of standard SNO 8069/91 are specially mentioned. As optimal solution of this problem it is supposed to accept corresponding STANAG standards that regulate this problematic.

Key words: propellants, chemical stability, standard.

\section{Uvod}

Pogonske eks plozivne materije (baruti i raketna goriva), kao i ostale eks plozivne materije (EM), poseduju visoki sadržaj energije zbog cega se cesto nazivaju i energetski materijali.

Zbog povišenog sadržaja energije pogonske EM su više ili manje termodinamic ki nestabilne, zbog cega su sklone laganoj termic koj de kompoziciji, cak i na sobnoj temperaturi. Procesi hemijskog razlaganja odvijaju se prema razlicitim mehanizmima, kao što su monomolekularni raspad, uz for miranje slobodnih radikala, konsekutivne reakcije izmedu slobodnih radikala, oksidacioni i hidroliticki procesi, itd. Vecina ovih procesa su egzotermni i autokatalitic ki [1]. Kao takvi mogu uzrokovati dva glavna proble ma:

- nestabilnost baruta i raketnih goriva $(R G)$, 
- termalnu eks ploziju, odnosno njihovo samozapalje nje u odredenim kriticnim uslovima.

Posle dica odigravanja ovih procesa je smanjenje veka upotrebe pogonskih EM. Pojam nestabilnost (sta renje) baruta i RG podrazumeva pad njihovih funkcionalnih i bezbednosnih karakteristika tokom skla dištenja.

Samozapalje nje EM može da se dogodi u slucaju kada je br zina oslobadanja toplote usled egzotermnih reakcija hemijske dekompozicije, koje se odvijaju u pogonskim EM, veca od brzine razmene toplote sa okolinom.

Vek upotrebe obic no se de finiše kao interval u kojem se pogonske eks plozivne materije mogu skla dištiti i primenjivati bez bilo kakve opasnosti. Da bi se on definisao moraju se poznavati vremena bezbednog skla dištenja i vremena pouzdanog funkcionisanja.

Vreme bezbednog skla dištenja ili hemijski vek upotrebe obuhvata period za koji se odredena pogonska EM može bezbedno skla dištiti bez ikakve opasnosti od samozapaljenja. Bezbedni vek je ogranicen intenzitetom reakcija termic ke dekompozicije (reakcijama starenja).

Vreme pouzdanog funkcionisanja (balisticki vek) je ste period u kojem se pogonska EM može bezbedno primenjivati i u kojem funkcionalne karakteristike ostaju u zahtevanim granicama.

Glavni faktori koji ogranicavaju vreme pouzdanog funkcionisanja su hemijsko sta renje pogonskih EM (gubitak energije) i fizic ko sta renje usled odvijanja razlicitih fizickih procesa (upijanje vla ge, difuzija, fazne promene, itd.) što dovodi do pada mehanic kih karakteristika (posebno važno kod raketnih goriva).
Radi toga se stabilnost baruta i RG mora detaljno ispitati pre nego što se krene $u$ njihovu proizvodnju, skla dištenje i la boraciju u ubojna sredstva (UbS), a zatim, tokom skla dištenja, mora se periodic no kontrolisati da bi se izbegle neželje ne posle dice usled moguceg samoza palje nja.

Sva is pitivanja moraju biti realizovana po strogo definisanoj proceduri koja se propisuje odgovarajucim standardima. $\mathrm{U}$ tom pogledu mi u poslednjih 15 godina zaostajemo u odnosu na svet. Poslednji važan standard koji je kod nas donešen je SNO 8069/91 koji reguliše ispitivanje hemijske stabilnosti baruta i RG [2], ali su tokom nje gove primene uoceni brojni nedostaci [3]. U isto vreme, u svetu, a pre svega u zemljama NATO i cla nicama Partnerstva za mir (NATO/PfP), in tenzivno se radilo na usavršavanju metodologije kontrole hemijske stabilnosti baruta i RG. Kao rezultat tih s straživanja u poslednjih pet godina usvojeno je nekoliko standarda grupe STANAG (Standardisation Agreement NATO/PfP) i tehnic kih publikacija kojima je regulisana ova problematika.

\section{Hemijsko starenje ba ruta i RG}

Problem he mijske stabilnosti narocito je izražen kod pogonskih EM na bazi NC i NG. Hemijsko sta renje pogonskih EM zapocinje kidanjem ve ze $\mathrm{O}-\mathrm{NO}_{2}$, pri cemu se formira azotdioksid i odgovarajuci alkoksil radikal [1]:

$\mathrm{R}-\mathrm{O}-\mathrm{NO}_{2} ? \quad \mathrm{R}-\mathrm{O} \cdot+\cdot \mathrm{NO}_{2}$

Alkoksil radikal, koji je vrlo reaktivan, stupa u konsekutivne reakcije sa najbližim mole kulima nitratnih estara. U slucaju NC glavni radikal R-O takode podleže unutrašnjim reakcijama stabilizacije 
cepanjem na male stabilne molekule $\mathrm{N}_{2}$, $\mathrm{N}_{2} \mathrm{O}, \cdot \mathrm{NO}, \cdot \mathrm{NO}_{2}, \mathrm{H}_{2} \mathrm{O}, \mathrm{H}_{2}, \mathrm{CO}_{2}, \mathrm{CO}$ :

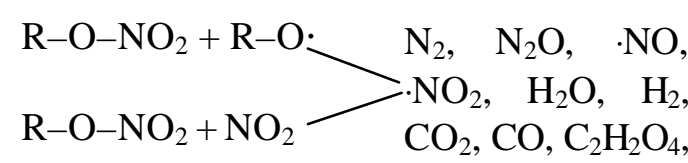

$$
\text { ... }
$$

Druga glavna reakcija de kompozicije je ste hidroliza nitratnog estra i formiranje azotne kiseline usled prisustva vlage i zaostale kiseline (koja nije potpuno uklonje na pri sintezi nitratnog estra):

$$
\mathrm{R}-\mathrm{O}-\mathrm{NO}_{2}+\mathrm{H}_{2} \mathrm{O} \stackrel{\mathrm{H}^{+}}{\longrightarrow} \mathrm{R}-\mathrm{OH}+\mathrm{HNO}_{3}
$$

Dalje reakcije dekompozicije izražene su hidroliticke reakcije, uzrokovane interakcijom izmedu nitro grupa i $\mathrm{N}_{2} \mathrm{O}_{4}$. Pri tome najpre dolazi do konverzije nitro gupe u nitrit nu gupu R-O-NO pracene hidrolizom $\mathrm{O}-\mathrm{NO}$ veze. Ova reakcija uocena je kod NG i ima znatno nižu energiju aktivacije od $71 \mathrm{~kJ} / \mathrm{mol} \mathrm{u}$ poredenju sa $100 \mathrm{~kJ} / \mathrm{mol}$ kod nitratne grupe. Zato je ona dominantna reakcija dekompozicije pri nižim temperaturama.

Neki od reakcionih produkata reakcija (1) i (2) dalje se transformišu u prisustvu vla ge i kiseonika:

$2 \cdot \mathrm{NO}+\mathrm{O}_{2}-2 \cdot \mathrm{NO}_{2}-\mathrm{N}_{2} \mathrm{O}_{4}$

$\cdot \mathrm{NO}+\cdot \mathrm{NO}_{2}+\mathrm{H}_{2} \mathrm{O}-2 \mathrm{HNO}_{2}$

$3 \cdot \mathrm{NO}_{2}+\mathrm{H}_{2} \mathrm{O}-2 \mathrm{HNO}_{3}+\cdot \mathrm{NO}$

Radikali i kiseline koje nastaju pri reakcijama opisanim relacija ma (1 do 6) izrazito uticu na samoubrzavanje (autokatalizu) reakcija dekompozicije nitratnih estara (2) i (3).

Dok se primarne homolitic ke reakcije ne mogu spreciti, konsekutivne reakcije (2) i (3) mogu se znatno usporiti ve-

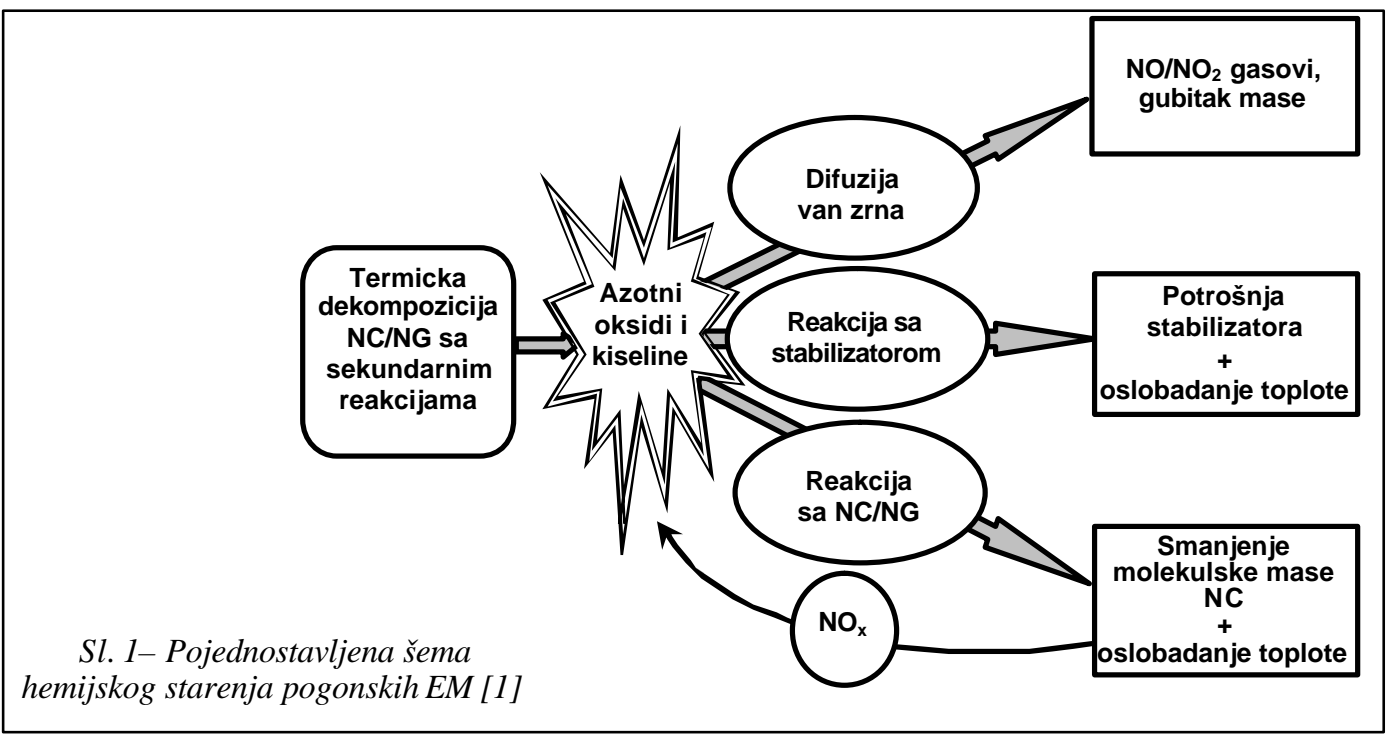


zivanjem ili eliminacijom kiselina, azotnih oksida i vode iz sistema. Ova cinje nica primenjuje se za stabilizaciju nitratnih estara. Najcešce korišceni stabilizatori su difenilamin (DFA) i etilcentralit (centralit I). Vrlo reaktivni azotni oksidi reaguju sa stabilizatorima, što dovodi do njihove potrošnje i osobadanja toplote.

Pojednostavlje na šema starenja pogonskih EM prikazana je na slici 1.

Sve me tode za is pitivanje he mijske stabilnosti pogonskih EM se, u osnovi, zasnivaju na pracenju tri parametra: oslobadanju azotnih oksida, brzini razvija nja toplote i potrošnje stabilizatora.

\section{Ispitivanje hemijske stabilnosti pogonskih EM u našoj zemlji}

Ispitivanje hemijske stabilnosti pogonskih EM u na šoj zemlji regulisano je standardom SNO 8069/91 [2], koji je nastao kao rezultat is traživanja ove problematike u ukviru zajednic kog projekta koji su realizovali Vojnotehnicka akademija i Vojnotehnicki institut u periodu od 1981. do 1990. godine.

Standard propisuje nacin prikupljanja uzorka za cuvanje u kolekcijama, obaveze nosioca razvoja, proizvodnje, kontrole, laboracije i skla dištenja baruta i raketnih goriva, metodologiju ispitivanja sa kriterijumima, kao i opis konkretnih metoda ispitivanja. Pri tome, posebno je regulisano is pitivanje hemijske stabilnosti u toku razvoja i proizvodnje, a posebno u toku skladištenja.

Prema ovom standardu u toku razvoja, zavisno od vrste, baruti i RG se ispituju prema metodama: grejanja na $100^{\circ} \mathrm{C}$; metilvioletnoj metodi na $134,5^{\circ} \mathrm{C}$; metodi po Bergman-Junku na $132^{\circ} \mathrm{C}$; metodi ubrzanog starenja i metodi merenja toplotne aktiv nosti (mikrokalorimetrija).
Treba istaci da je metoda toplotne aktivnosti rezultat domaceg is traživanja $\mathrm{i}$ razvoja. Njen princip je u odredivanju kriticnog precnika is pitivanog baruta kod kojeg može doci do samozapaljenja u uslovima skla dištenja.

Za prijem baruta i RG u serijskoj proizvodnji primenjuju se pr ve tri metode, a za pracenje hemijske stabilnosti tokom skladištenja metode na rednom broju $1 \mathrm{i}$ 5, kao i me toda odredivanja sadržaja stabilizatora. Pri tome je regulisano da se prva kontrola vrši 10 godina nakon proizvodnje, a za tim na svakih 5 godina. Takode, prema standardu u toku skla dištenja ne prati se hemijska stabilnost baruta koji su la borisani u municiji kalibra do $30 \mathrm{~mm}$.

Kriterijumi za ocenu hemijske stabilnosti prikazani su u tabelama 1 i 2 .

$\mathrm{Na}$ osnovu is kustva u petnaestogodišnjoj primeni SNO 8069/91 uoceni su i nje govi brojni nedostaci, medu kojima su najznacajniji:

- nesagla snost rezultata izmedu pojedinih me toda;

- sla ba reproduktivnost rezultata koje daje metoda mikrokalorimetrije;

- nije regulisano ponavlja nje is pitivanja sa uzor cima iz UbS, u slu caju kada se dobijaju sumnjivi rezultati sa uzorcima iz kolekcija;

- nije propisana interpretacija rezultata u slucaju kada su oni, za istu seriju baruta, razliciti u razlicitim kolekcija ma;

- nije propisan postupak is pitivanja kada se u barutu nalaze dva razlicita stabilizatora, od kojih je dan ima ulogu plastifikatora, ali evidentno povecava i hemijsku sta bilnost baruta;

- nacin kategorizacije baruta i RG je diskutabilan, itd. 
S obzirom na to da ovi ne dostaci znatno umanjuju pouzdanost dobijenih rezultata, neophodno je što pre pristupiti usavršavanju metodologije kontrole hemijske stabilnosti baruta i RG radi povecanja bezbednosti uskla dištenih UbS.

Kriterijumi za ocenu hemijske stabilnosti jednobaznih baruta

\begin{tabular}{|c|c|c|c|c|}
\hline $\begin{array}{c}\text { DFA } \\
(\%)\end{array}$ & $\begin{array}{c}\text { Aktivni } \\
\text { stabilizator } \\
(\%)\end{array}$ & \begin{tabular}{|c|} 
Termicka \\
aktivnost \\
Poredenje $\mathrm{D}_{\mathrm{c}}$ i D \\
$(\mathrm{m})$
\end{tabular} & $\begin{array}{l}100^{\circ} \mathrm{C} \\
\text { (dan) }\end{array}$ & $\begin{array}{c}\text { Kategorija } \\
\text { baruta }\end{array}$ \\
\hline$\geq 0,5$ & - & $\mathrm{D}_{\mathrm{c}}(60)>\mathrm{D}$ & $\geq 4$ & 50 \\
\hline \multirow[t]{7}{*}{$\geq 0,2$} & \multirow{4}{*}{$\geq 0,5$} & $\mathrm{D}_{\mathrm{c}}(60)>\mathrm{D}$ & $<4$ & 51 \\
\hline & & $\mathrm{D}_{\mathrm{c}}(60)<\mathrm{D}$ & & 52 \\
\hline & & $\mathrm{D}_{\mathrm{c}}(50)<\mathrm{D}$ & & 58 \\
\hline & & $\mathrm{D}_{\mathrm{c}}(40)<\mathrm{D}$ & & 59 \\
\hline & \multirow{3}{*}{$<0,5$} & $\mathrm{D}_{c}(60)>\mathrm{D}$ & & 52 \\
\hline & & $\mathrm{D}_{\mathrm{c}}(60)<\mathrm{D}$ & & 58 \\
\hline & & $\mathrm{D}_{\mathrm{c}}(50)>\mathrm{D}$ & & 59 \\
\hline \multirow{5}{*}{$\leq 0,2$} & \multirow{3}{*}{$\geq 0,3$} & $D_{c}(60)>D$ & & 52 \\
\hline & & $\mathrm{D}_{\mathrm{c}}(60)<\mathrm{D}$ & & 58 \\
\hline & & $\mathrm{D}_{\mathrm{c}}(50)>\mathrm{D}$ & & 59 \\
\hline & \multirow{2}{*}{$<0,3$} & $D_{c}(60)>D$ & & 58 \\
\hline & & $\mathrm{D}_{\mathrm{c}}(60)<\mathrm{D}$ & & 59 \\
\hline
\end{tabular}

Tabela 2 Kriterijumi za ocenu hemijske stabilnosti dvobaznih i trobaznih baruta

\begin{tabular}{|c|c|c|c|}
\hline \begin{tabular}{|c|} 
Sadržaj \\
stabilizatora \\
$(\%)$ \\
\end{tabular} & \begin{tabular}{|c|} 
Termicka aktivnost \\
Poredenje $\mathrm{D}_{\mathrm{c}}$ i D \\
$(\mathrm{m})$
\end{tabular} & $100^{\circ} \mathrm{C}$ (dan) & $\begin{array}{c}\text { Kategorija } \\
\text { baruta }\end{array}$ \\
\hline$\geq$ (poc. $-50 \%)$ & $D_{c}(60)>D$ & $\begin{array}{c}\geq 4 \\
(2,5 \text { za NGB })\end{array}$ & 50 \\
\hline \multirow{4}{*}{$\geq$ (poc. $-70 \%$ ) } & $D_{c}(60)>D$ & \multirow{4}{*}{$\begin{array}{c}<4 \\
(2,5 \text { za NGB })\end{array}$} & 51 \\
\hline & $D_{c}(60)>D$ & & 52 \\
\hline & $D_{c}(60)>D$ & & 58 \\
\hline & $D_{c}(60)>D$ & & 59 \\
\hline \multirow{3}{*}{$\geq$ (poc. $-80 \%)$} & $D_{c}(60)>D$ & & 52 \\
\hline & $D_{c}(60)>D$ & & 58 \\
\hline & $D_{c}(60)>D$ & & 59 \\
\hline
\end{tabular}

\section{Ispitivanje hemijske stabilnosti prema NATO metodologiji}

U ze mlja ma cla nicama NATO, kao i u onima koje su cla nice asocijacije Partnerstvo za mir (NATO/PfP), ispitivanje hemijske stabilnosti pogonskih EM regulisano je odgovarajucim STANAG standardima, ciji je pregled dat u tabeli 3 .
Tabela 3

Ispitivanja hemijske stabilnosti prema NATO standardima

\begin{tabular}{|c|l|}
\hline $\begin{array}{c}\text { Oznaka } \\
\text { standarda }\end{array}$ & \multicolumn{1}{|c|}{ Naziv standarda } \\
\hline $\begin{array}{c}\text { STANAG } \\
4170\end{array}$ & $\begin{array}{l}\text { Principi i metodologija za karakterizaciju } \\
\text { eksplozivnih mat erija za vojnu primenu }\end{array}$ \\
\hline $\begin{array}{c}\text { STANAG } \\
4117\end{array}$ & $\begin{array}{l}\text { Eksplozivi, procedure za testove stabilnosti i zah- } \\
\text { tevi za pogonske EM stabilisane sa DFA i/ili EC }\end{array}$ \\
\hline $\begin{array}{c}\text { STANAG } \\
4527\end{array}$ & $\begin{array}{l}\text { Eksplozivi, hemijska stabilnost, pogonske } \\
\text { EM na bazi NC, postupak za hem. stab., pro- } \\
\text { cedure za procenu hemijskog veka i tempera- } \\
\text { turne zavisnosti brzine utrokka stabilizatora }\end{array}$ \\
\hline $\begin{array}{c}\text { STANAG } \\
4541\end{array}$ & $\begin{array}{l}\text { Eksplozivi, NC baruti koji sadrže i NG, sta- } \\
\text { bilisani sa DFA, test stabilnosti i krit erijum }\end{array}$ \\
\hline $\begin{array}{c}\text { STANAG } \\
4556\end{array}$ & Eksplozivi, vakuum test stabilnosti \\
\hline $\begin{array}{c}\text { STANAG } \\
4582\end{array}$ & $\begin{array}{l}\text { Eksplozivi, NC i NG baruti, test stabilnosti i zah- } \\
\text { tevi prema metodi HFC (heat flow calorimetry) }\end{array}$ \\
\hline
\end{tabular}

Pored ovih standarda, znacajne su i sle dece tehnicke publikacije:

1. AOP-7 (Allied Ordnance Publication) - koja sadrži uputstvo o testovima i podacima koji se zahtevaju pri karakterizaciji eks plozivnih materija za vojnu primenu u NATO/PfP zemljama,

2. AOP 48 koja sadrži sve procedure za ispitivanje hemijske stabilnosti pogonskih EM, kao i zahteve za metodu utroška stabiliza tora.

STANAG 4170 je osnovni standard koji propisuje sistem karakterizacije EM za vojnu primenu, odnosno za razlicite EM definiše parametre koji se moraju ispitati pre ne go što se mogu primenjivati, kao i metode (odgovarajuci STANAG) po kojima ce se ti parametri odredivati [4].

STANAG 4117 standardizuje ispitivanje he mijske sta bilnosti pogonskih EM koje su stabilisane sa difenil aminom (DFA), etilcentralitom (EC) ili njihovom sme šom [5]. Poš to je utvrdeno da se kod baruta koji su stabilisani sme šom DFA i EC pri starenju najpre troši samo DFA, i procena he mijske sta bilnosti je uskladena sa nje govom potrošnjom. Odredivanje sadržaja EC predvideno je samo kao dopunsko is pitivanje. 
Prema ovom standardu, garancija da ce is pitivana pogonska EM zadržati hemijsku stabilnost u uslovima skla diš te nja najmanje 5 ili 10 godina dobija se ako su ispunjeni sle deci uslovi:

1. Jednobazni baruti stabilisani sa DFA ili sme šom DFA i EC izlažu se ubrzanom starenju na $65,5^{\circ} \mathrm{C}$, u trajanju od 60 ili 120 dana, nakon cega se odreduje sadržaj stabilizatora.

Da bi barut u narednih 5 godina bio hemijski stabilan nakon 60 da na greja nja na $65,5^{\circ} \mathrm{C}$, pad sadržaja DFA ne sme biti veci od $0,5 \%$, a nje gova kolicina u barutu ne sme biti manja od $0,3 \%$.

Barut ce imati zadovoljavajucu hemijsku stabilnost $\mathrm{u}$ narednih 10 godina ako za dovolji je dan od sle de cih uslova:

- pad sadržaja DFA nakon 60 dana grejanja na $65,5^{\circ} \mathrm{C}$ ne sme biti veci od $0,3 \%$, a sadržaj DFA u barutu ne sme biti manji od $0,6 \%$;

- pad sadržaja DFA nakon 120 dana grejanja na $65,5^{\circ} \mathrm{C}$ ne sme biti veci od $0,5 \%$, a sadržaj DFA u barutu ne sme biti manji od $0,3 \%$.

2. Baruti stabilisani sa EC izlažu se ubrzanom starenju na $65,5^{\circ} \mathrm{C}$, u trajanju od 60 ili 120 dana, nakon cega se odreduje sadržaj sta bilizatora.

Da bi barut u narednih pet godina bio he mijski stabilan, nakon 60 da na grejanja na $65,5^{\circ} \mathrm{C}$ pad sadržaja EC ne sme biti veci od $1 \%$, a sadržaj stabilizatora u barutu ne sme biti manji od 50\% sadržaja stabilizatora pre greja nja, a ni u kom slucaju ne sme biti manji od 0,3\%.

Barut ce imati zadovolja vajucu hemijsku stabilnost $\mathrm{u}$ narednih 10 godina ako za dovolji je dan od sle de cih uslova:

- pad sadržaja EC nakon 60 dana grejanja na $65,5^{\circ} \mathrm{C}$ ne sme biti veci od
$1 \%$, a sadržaj DFA u barutu ne sme biti manji od $75 \%$ sadržaja stabilizatora pre grejanja, a ni ukom slucaju ne sme biti manji od $0,7 \%$;

- pad sadržaja EC nakon 120 dana grejanja na $65,5^{\circ} \mathrm{C}$ ne sme biti veci od $1 \%$, a sadržaj DFA u barutu ne sme biti manji od $50 \%$ sadržaja stabilizatora pre grejanja, a ni ukom slucaju ne sme biti manji od $0,3 \%$.

Treba nagla siti da se u sadržaj DFA uzima u obzir i $85 \%$ kolicine $\mathrm{N}$-nitrozo difenilamina.

U standardu su opisane procedure za odredivanje sadržaja stabilizatora po metodi HPLC, spektrofotometrije i potenciometrijske titracije.

STANAG 4527 de finiše metodologiju prognoziranja hemijske stabilnosti i temperaturne za visnosti potrošnje stabilizatora u pogonskim EM [6]. Radi toga se vrši ubrzano starenje pogonskih EM na najmanje tri temperature $\mathrm{u}$ in tervalu od 40 do $80^{\circ} \mathrm{C}$, pri cemu temperaturni interval ne sme biti manji od $10^{\circ} \mathrm{C}$. Vreme starenja utvrduje se tako da se obezbedi da pad stabilizatora bude najmanje $20 \%$ u odnosu na pocetni sadržaj, a najviše $80 \%$.

$\mathrm{Pad}$ koncentracije stabilizatora sa vremenom ana lizira se u skla du sa mehanizmom reakcije nultog i prvog reda:

- nulti red

$$
\frac{-d C}{d t}=k C_{0}
$$

gde je:

$k$ - konstanta brzine reakcije za datu temperaturu,

$C_{0}$ - pocetna koncentracija stabilizatora,

$C$ - koncentracija stabilizatora nakon odredenog vremena $t$. 
Integracijom izraza (7) dobija se:

$\frac{C_{0}-C}{C_{0}}=k t$

Izraz (8) omogucuje da se odredi konstanta $k$ za odredenu temperaturu, ako se poznaje promena sadržaja stabilizatora sa vremenom.

- prvi red

$\frac{-d C}{d t}=k C$

Integracijom izraza (9) dobija se:

$\ln \frac{C_{0}}{C}=k t$

Analogno prethodnom slucaju konstanta $k$ odreduje se iz nagiba prave $\ln \left(\mathrm{C}_{0} / \mathrm{C}\right)-t$. Pri tome se prihvata da se reakcija odvija po onom mehanizmu koji bolje opisuje promenu sadržaja stabilizatora u barutu i po nje mu se dalje vrši analiza.

$\mathrm{Na}$ osnovu odredenih vrednosti konstanti na više temperatura (najmanje tri), pomocu Arenijusovog izraza, odreduje se vrednost energije aktivacije, $E$ :

$k=A e^{-\frac{E}{R T}}$

odnosno:

$\ln k=\ln A-\frac{E}{R T}$

gde je:

$A$ - predeksponencijalni faktor $(\mathrm{J} / \mathrm{mol})$,

$R$ - univerzalna gasna konstanta $(8,314$ $\mathrm{J} / \mathrm{molK})$.
Na osnovu izracunatog vremena $t_{s t}$, koje je potrebno da sadržaj stabilizatora padne na definisanu vrednost na temperaturi starenja $T_{s t}$ (izraz 8 ili 10) racuna se vreme $t_{s k}$, za koje ce sadržaj stabilizatora pasti na tu vrednost na temperaturi skla dištenja, $T_{s k}$ :

$t_{s k}=t_{s t} e^{\frac{E}{R}\left(\frac{1}{T_{s k}}-\frac{1}{T_{s t}}\right)}$

Kao srednja temperatura skla dištenja uzima se $25^{\circ} \mathrm{C}$.

STANAG 4541 propisuje proceduru ispitivanja hemijske stabilnosti pogonskih EM koje sadrže do $15 \%$ NG i stabilisane su sa DFA [7].

Prognoziranje hemijskog veka upotrebe vrši se prema STANAG 4527.

Za ovu vrstu baruta utvrdeno je da odstupaju od kriterijuma za de setogodišnju garanciju he mijske stabilnosti prema STANAG 4117. Medutim, u uslovima prirodnog starenja utvrdeno je da ostaju hemij ski stabilni i više od 10 godina.

U skladu s tim, utvrdeni su i kriterijumi za pogonske EM koje sadrže do $15 \%$ NG i stabilisane sa DFA.

Pri skla diš tenju na srednjoj temperaturi od $25^{\circ} \mathrm{C}$ baruti ce biti stabilni najmanje 10 godina, ako nakon 60 dana starenja na $60^{\circ} \mathrm{C}$ za dovolje sle dece kriterijume:

- pad efektivnog stabilizatora ne sme biti veci od $50 \%$ u odnosu na pocetni sadržaj,

- kolicina efektivnog stabilizatora u barutu ne sme biti manja od $0,5 \%$.

STANAG 4556 propisuje proceduru $\mathrm{za}$ ispitivanje termicke stabilnosti EM prema va kuum-te stu stabilnosti koji se zasniva na merenju zapremine oslobodenih 
gasova pri zagrevanju uzorka odredeno vreme na povišenoj temperaturi [8]. Uslovi ispitivanja mogu biti razliciti, što za visi od vrste EM, a i od konkretnih zahteva. Uobicajeno je da temperatura ispitivanja jednobaznih baruta iznosi $100^{\circ} \mathrm{C}$, a dvobaznih $90^{\circ} \mathrm{C}$ u trajanju od 40 sati. Pri tome, dozvolje na kolicina azotnih oksida definiše se posebno za svaku vrstu EM.

STANAG 4582 propisuje proceduru utvrdivanja hemijske stabilnosti pogonskih EM na osnovu metode merenja toplotnog fluksa - HFC (Heat Flow Calorimetry) na povišenim temperaturama za najmanje 10 godina na prosecnoj temperaturi skla diš tenja od $25^{\circ} \mathrm{C}$ [9].

Pogonske EM uskla dištene na $25^{\circ} \mathrm{C}$ moraju zadovoljiti sle dece kriterijume da bi zadržale hemijsku stabilnost minimal no 10 godina:

- maksimalni toplotni fluks, pri merenju na odredenoj povišenoj temperaturi izmedu vremena koje odgovara oslobodenoj toploti od $5 \mathrm{~J} / \mathrm{g}$ i izracunatog vremena trajanja eks perimenta (jednacina 14) ne sme preci vrednost toplotnog fluksa, utvrdenu na osnovu sle dece jednacine (15):

$$
\begin{aligned}
& t_{m}=t_{25} e^{\frac{E_{1}}{R T_{m}} C} \\
& P_{g}=P_{71} e^{\frac{E_{1}}{R}\left(\frac{1}{T_{71}}-\frac{1}{T_{m}}\right)}
\end{aligned}
$$

gde je:

$t_{m}$ - trajanje te sta (dan),

$t_{25}$ - vreme skladištenja na $25^{\circ} \mathrm{C}(3652,5$ dana $=10$ godina),

$E_{1}$ - energija aktivacije u gornjem temperaturnom in tervalu $(120 \mathrm{~kJ} / \mathrm{mol})$, $R$ - gasna konstanta $(0,008314 \mathrm{~kJ} / \mathrm{mol} \mathrm{K})$, $C-$ konstanta $=46,713$,
$T_{m}$ - temperatura eks perimenta $(K)$,

$T_{71}=344 \mathrm{~K}\left(=71^{\circ} \mathrm{C}\right)$,

$P_{71}$ - granica toplotnog fluksa na $71^{\circ} \mathrm{C}$ $(39 \mu \mathrm{W} / \mathrm{g})$,

$P_{g}-$ granica toplotnog fluksa pri $\mathrm{T}_{\mathrm{m}}$ $(\mu \mathrm{W} / \mathrm{g})$,

Primer tipic nog dija grama is pitivanja toplotnog fluksa prikazan je na slici 2 .

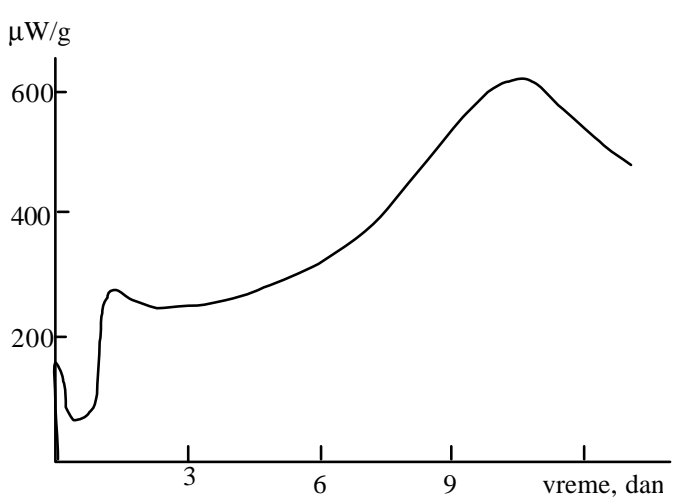

Sl. 2 - Toplotni fluks dvobaznog baruta na $89^{\circ} \mathrm{C}$ (stabilisan sa DFA)

\section{Komparativna analiza}

Vec na prvi pogled može se zakljuciti da je naša zemlja u velikom zaostatku u pogle du uredenja, odnosno standardizacije proble matike ispitivanja eks plozivnih materija. Pre svega, nedostaje osnovni standard, analogan STANAG 4170 , koji bi propisao sve neophodne testove i metodologiju ispitivanja eksplozivnih materija pre nego što udu u vojnu primenu, kao i odgovornu instituciju koja ce da realizuje ta is pitivanja.

Što se tice ispitivanja hemijske stabilnosti pogonskih EM, može se konstatovati da je SNO 8069/91, iako je donesen pre 15 godina, još uvek aktuelan i po svojoj suštini slican NATO me todologiji. Medutim, buduci da od nje govog dono- 
šenja više ništa nije uradeno na usavršavanju metodologije i otkla njanju uocenih nedostataka, ako se analiziraju pojedine metode i kriterijumi uocice se i brojne razlike u odnosu na odgovarajuce STANAG standarde.

Pre svega, standard SNO predvida posebne metode $\mathrm{u}$ toku razvoja pogonskih EM, a posebne za vreme skladištenja, dok NATO standardi regulišu metodologiju ispitivanja od trenutka prijema EM za vojnu primenu. Pored toga, periodika ispitivanja se donekle razlikuje. U našoj zemlji prvo ispitivanje se obavlja nakon 10 godina od trenutka proizvodnje, a zatim svakih pet godina, dok se prema NATO standardima najcešce vrši svakih 10 godina, a u nekim slucaje vima i na pet godina.

Razlika u metodologiji pracenja hemijske stabilnosti, od trenutka prijema, ogle da se u cinjenici da se kod nas za pracenje he mijske stabilnosti još uvek primenjuje metoda grejanja na $100^{\circ} \mathrm{C}$, a nije predviden vakuum test stabilnosti koji propisuje STANAG 4556. Me dutim, s obzirom na to da su principi obe metode $u$ osnovi slic ni, može se zakljuciti da ova razlika nije od bitnog znacaja za pouzdanost utvr divanja he mijske stabilnosti.

Znacajna razlika je u primeni metode ubrzanog starenja, koja se kod nas primenjuje samo u fazi razvoja pogonskih $\mathrm{EM}$, dok je prema NATO metodologiji ova metoda prakticno osnova pracenja sadržaja stabilizatora tokom skla dištenja, na osnovu koje se daje garancija za hemijsku stabilnost za narednih 10 (ili 5) godina i predvida vek upotrebe pogonskih EM. Na ovaj nacin dobija se mnogo pouzdanija slika o hemijskoj stabilnosti, jer se uzimaju u obzir parametri koji to- kom skla dištenja dovode do promene stanja baruta (klimatski uslovi, stepen dekompozicije, autokataliticki procesi, itd.), a koji uticu i na promenu mehanizma potrošnje satabilizatora.

Naša najnovija istraživanja to su i potvrdila [10]. Naime, na osnovu rezultata ubrzanog sta renja, po pravilu se dobija mnogo duži prognozirani vek trajanja baruta u odnosu na barut u realnim uslovima skla dištenja.

Bez obzira na to što su za snovane na istoj teoriji (toplotna teorija eksplozije) postoje velike razlike i izmedu naše $\mathrm{i}$ STANAG me tode mikrokalorimetrije. Pre svega, razlikuju se prin cipi me renja br zine razvijanja toplote kod naše metode i metode HFC koja je propisana standardom STANAG 4582. Dok metoda HFC meri toplotni fluks sa površine uzorka, naša metoda meri temperaturu $u$ geometrijskom centru uzor ka na osnovu koje se vrši preracunavanje na brzinu razvijanja toplote, što je cini mnogo nepreciznijom. Pored toga, razliciti su i kriterijumi stabilnosti. Kod na še metode to je velicina kritic nog precnika, a kod STANAG metode velicina toplotnog fluksa.

Ipak, najveci nedostatak naše metode, koji je potvrden u njenoj petnaestogodišnjoj primeni, jeste izrazito velika nereproduktivnost rezultata, što ozbiljno dovodi u pitanje opravdanost nje ne dalje primene.

Jedno rešenje je da se izvrši nje no usavršavanje, radi otklanja nja ne dostataka, a drugo, koje je mnogo opravdanije, da se nabavi adekvatni uredaj HFC $i$ is pitivanje vrši po standardu STANAG 4582.

Uzimajuci u obzir tendenciju naše zemlje ka NATO integracijama, najbolje je da se odmah otpoc ne sa realizacijom neophodnih aktivnosti radi što hitnije pri- 
mene NATO metodologije za pracenje hemijske stabilnosti pogonskih EM. Bez primene NATO standarda nece se moci ni realizovati nikakav izvoz, kako eksplozivnih materija, tako i ubojnih sredstava u kojima su one la borisane. U tom smislu, potrebno je najpre zva nic no odrediti odgovornu instituciju za to, izvršiti opremanje ade kvatnom opremom i zapoceti primenu STANAG standarda. Naša prednost je u tome što imamo bogato iskustvo i znanja iz ove proble matike, kao i izuzetno strucan kadar, što je garancija da ce se nova me todologija vrlo lako prihvatiti i primeniti.

\section{Zakljucak}

Zbog potencijalne opa snosti od samozapalje nja baruta i RG u uskla dištenim UbS, u svetu a i kod nas, velika pažnja pokla nja se kontroli njihove he mijske stabilnosti. Proces hemijske dekompozicije nitroestara, pre sve ga nitroceluloze, toliko je složen i zavisan od mnogih parametara da još uvek nije pouzdano utvr den njen mehanizam. To namece potrebu za stalnim istraživanjem ove proble matike i usavršavanje me todologije za pracenje he mij ske stabilnosti.

$\mathrm{Na}$ osnovu petnaestogodišnjeg iskustva u primeni naše me todologije uoceni su nje ni brojni nedostaci u standardu SNO 8069/91, koji znatno umanjuju pouzdanost dobijenih rezultata, što namece potrebu za nje govom korekcijom i dopunom, a sve radi povecanja bezbednosti uskla diš tenih UbS.

$S$ obzirom na tendenciju na še zemlje ka NATO integracijama, najbolje rešenje je da se prihvati NATO metodologija za pracenje hemijske stabilnosti pogonskih EM.

Literatura:

[1] Folly, P.; Mäder, P.: Propellant Chemistry, Chimia, 6, Vol. $58,2004$.

[2] SNO 8069/91 - Pracenje hemijske stabilnosti baruta i raketnih goriva, Biro SIM.

[3] Grbovic, L.: Analiza rezultata odredivanja sadržaja stabilizatora u prirodno starenim barutima, VTG, 2/2006.

[4] STANAG 4170: Princi ples and met hodology for the qualification of explosive materials for military use, NATO Military agency for standardization (MAS), Brussels, 2001.

[5] STANAG 4117: Explosives, stability test procedures and requirements for propellants stabilized with DPA, EC (CI) or a mixture of both, NATO Military agency for standardization (MAS), Brussels, 1998.

[6] STANAG 4527 - Explosive, chem. stab., NC based propellants, procedure for as sessment of chemical life and temperature dependance of stabiliser consumption rates, NATO Military agency for standardization (MAS), Brussels, 2000.

[7] STANAG 4541 - Explosives, NC based propellants containing NG and stabilised with DPA, stability test procedures and requirements, NATO Military agency for standardization (MAS), Brussels, 2003.

[8] STANAG 4556 - Explosives: Vacuum stability Test, NATO Military agency for standardization (MAS), Brussels, 1999.

[9] STANAG 4582 - Explosives, NC based propellants, stability test procedure and requirements using HFC, NATO Military agency for standardization (MAS), Brussels, 2004.

[10] Grbovic, L.: Istraživanje hemijske stabilnosti malodimnih baruta, doktorska disertacija, VA, Beograd, 2006. 